\title{
Retraction Note: The effects of curing medium on flexural strength and water permeability of concrete incorporating $\mathrm{TiO}_{2}$ nanoparticles
}

\author{
Ali Nazari
}

Accepted: 1 August 2021/Published online: 9 August 2021

(C) RILEM 2021

\section{Retraction note to: \\ Materials and Structures (2021) \\ https://doi.org/10.1617/s11527-010-9664-y}

The Editor-in-Chief has retracted this Article.

After investigation, it has been found that Figures 2 and 3 show overlap with Figures 1 and 2 (respectively) of a previously published article by different authors [1].

Additionally, it has been found that some of the figures and tables have been reproduced in other, laterdated publications, and in some cases are identified in those publications as representing materials different from those described in the paper of concern. Specifically:

Table 1 showing the chemical and physical properties of Portland Cement has been duplicated in later publications [2-4] (among others) with no reference to this article;

Figures 2 and 3 appear identical to those published in $[5,6]$;

Figure 2 has similarities with Figure 2 in [3] when rotated, despite representing different nanoparticles;

The original article can be found online at https:// doi.org/10.1617/s11527-010-9664-y.

\section{A. Nazari $(\bowtie)$}

Department of Technical and Engineering Sciences, Islamic Azad University (Saveh Branch), Saveh, Iran e-mail: alinazari84@aut.ac.ir
Figure 7a has similarities with Figure 8(2)a of [7] and Figure 3a of [8]; and

Table 7 has been partially reproduced in Table 6 of [9] without any cross-reference.

For these reasons, the Editor-in-Chief no longer considers the data underlying the article to be reliable.

Ali Nazari has not responded to any correspondence from the Publisher about this retraction.

\section{References}

1. Jo BW, Kim CH, Tae GH, Park JB (2007) Characteristics of cement mortar with nano-SiO $\mathrm{S}_{2}$ particles. Constr Build Mater 21(6):1351-1355. https://doi.org/10.1016/j.conbuildmat. 2005.12.020

2. Nazari A, Riahi S (2013) RETRACTED ARTICLE: The effects of $\mathrm{ZrO} 2$ nanoparticles on strength assessments and water permeability of concrete in different curing media. J Exp Nanosci 8(4):413-433

3. Riahi S, Nazari A (2011) RETRACTED: Physical, mechanical and thermal properties of concrete in different curing media containing $\mathrm{ZnO}_{2}$ nanoparticles. Energy and Buildings 43(8):1977-1984

4. Nazari A, Riahi S (2012) $\mathrm{SiO} 2$ nanoparticles' effects on properties of concrete using ground granulated blast furnace slag as binder. Mag Concr Res 64(4):295-306

5. Nazari A, Riahi S (2010) The effect of $\mathrm{TiO}_{2}$ nanoparticles on water permeability and thermal and mechanical properties of high strength self-compacting concrete. Mater Sci Eng A 528(2):756-763

6. Nazari A, Riahi S (2011) RETRACTED: $\mathrm{TiO}_{2}$ nanoparticles effects on physical, thermal and mechanical properties of self 
compacting concrete with ground granulated blast furnace slag as binder. Energy and Buildings 43(4):995-1002

7. Nazari A, Riahi S (2011) RETRACTED: Abrasion resistance of concrete containing $\mathrm{SiO}_{2}$ and $\mathrm{Al}_{2} \mathrm{O}_{3}$ nanoparticles in different curing media. Energy Build. 43(10):2939-2946

8. Rafieipour MH, Nazari A, Mohandesi MA, Khalaj G (2012) Improvement compressive strength of cementitious composites in different curing media by incorporating $\mathrm{ZrO}_{2}$ nanoparticles. Mater Res 15(2):177-184
9. Nazari A, Riahi S (2011) RETRACTED: The effects of $\mathrm{TiO}_{2}$ nanoparticles on properties of binary blended concrete. J Compos Mater 45(11):1181-1188

Publisher's Note Springer Nature remains neutral with regard to jurisdictional claims in published maps and institutional affiliations. 